\title{
AS DISPUTAS COLONIAIS E NEOCOLONIAIS EM TORNO DO FUTEBOL: Portugal e França, dois casos significativos
}

\author{
THE COLONIAL AND NEOCOLONIAL DISPUTES \\ AROUND FOOTBALL: \\ Portugal and France, two significant cases
}

\author{
Lucas Martins Santos Melo*
}

\begin{abstract}
Resumo
Uma das características da diáspora africana é o movimento voluntário de pessoas para novas regiões, onde, geralmente, há uma demanda de mão de obra específica. Sendo o futebol uma das ocupações profissionais mais específicas que existe e dado o crescente número de jogadores africanos atuando nos grandes centros do futebol mundial, decidimos fazer uma breve investigação para aferir essa relação entre diáspora e futebol. Dessa forma, escolhemos dois países que possuem uma extensa comunidade e uma larga tradição de recepcionar imigrantes, dentre outras categorias profissionais, a de jogador de futebol. Referimo-nos aos casos de Portugal e da França, dois países que adotaram o sistema legal dos assimilados, que tiveram um largo conjunto de territórios, principalmente na África, e que usufruem proficuamente dos "pés de obra" das colônias de outrora. Este artigo, elaborado a partir de uma literatura científica sobre o tema e dados quantitativos, tem a intenção de mostrar os usos coloniais e neocoloniais do futebol empreendidos por estes países e traçar uma trajetória histórica correspondente para tal uso.
\end{abstract}

Palavras-chave: Futebol. Neocolonialismo. Portugal. França.

\begin{abstract}
One of the characteristics of the African Diaspora is the voluntary movement of people to new regions, where there is usually a demand for specific labor. As football is one of the most specific occupations in the world, and given the increasing amount of African players working in the major centers of world football, we have decided to make a brief research to assess this relation between Diaspora and football. In this way, we chose two countries that have an extensive community and a long tradition of receiving immigrants, among other professional categories, that of footballers. We refer to the cases of Portugal and France, two countries that have adopted assimilates' legal system, which have had a large set of territories, mainly in Africa, and who have profited from the colonies' labor of the past. This article, based on a scientific literature on the subject and quantitative data, is intended to show the colonial and neocolonial uses of football undertaken by these countries and to draw a corresponding historical trajectory for such use.
\end{abstract}

Key words: Football (Soccer). Neocolonialism. Portugal. France.

\footnotetext{
“Mestre em Antropologia Social em 2016 pela Universidade Federal de Sergipe (UFS). E-mail: lucasmsmelo@ gmail.com.
} 


\section{Introdução}

Em 2014, realizou-se a XX edição da Copa do Mundo, pródiga em bons jogos, bonitos gols e estádios cheios, na qual presenciamos também exibições de "amor à pátria" e "defesa das cores nacionais", inerentes à própria competição. Mas, além do patriotismo das arquibancadas, observou-se nitidamente a presença de estrangeiros nas equipes nacionais, jogadores que passam pelo processo de naturalização com o objetivo de defender uma seleção que não representa a localidade onde nasceu. No entanto, dessa "nouvelle vague", o que mais chama atenção da imprensa é a presença de negros nas equipes europeias e com isso algumas críticas emergiram por parte das respectivas populações quanto a esse fato.

O Mundial de futebol é um momento propício a se pensar sobre as questões do nacionalismo, pois, para o senso comum, já ficou caracterizado como o rótulo identificador de uma nação que aparece quadrienalmente. É o período em que "a imaginária comunidade de milhões parece mais real na forma de um time de onze pessoas com nome. O indivíduo, mesmo aquele que apenas torce, torna-se o próprio símbolo da sua nação" (HOBSBAWM, 2011, p.171). Isso nos suscitou a pesquisar um pouco mais sobre este assunto, a presença de jogadores negros no futebol das ex-metrópoles, seja nas seleções ou nas ligas profissionais.

Escolhemos como recorte empírico os casos de Portugal e da França, dois países que tiveram um largo conjunto de territórios, principalmente na África, e que usufruem proficuamente, ainda nos dias atuais, dos "pés de obra" das colônias de outrora. Ambos os países mantiveram sob jugo seus territórios ultramarinos entre meados do século XIX até a segunda metade do século XX. No caso português, a ruptura foi traumática resultando na Guerra Colonial, que só findou com a Revolução dos Cravos de 1974 na metrópole e a deposição do governo salazarista.

O futebol foi uma ferramenta muito utilizada para criar laços culturais entre a metrópole e as colônias. Ele se desenvolveu aliado aos empreendimentos tanto estatais como privados, alguns patrocinando o fomento do esporte, dessa maneira também com a intenção de controlar as relações trabalhistas; e também, junto às missões religiosas pelo interior, propagando o tripé: educação, disciplina e atividade física (DOMINGOS, 2006). Nas possessões portuguesas, a priori, o esporte foi difundido fortuitamente através dos administradores coloniais, comerciantes, missionários, imigrantes de toda sorte, sendo incorporado paulatinamente às práticas cotidianas da população local. A partir daí é que ele foi usado pelos colonialistas para impor sua posição hegemônica, a serviço das suas intenções. Por exemplo, em Moçambique, o futebol foi apresentado pelos missionários católicos, sendo estruturado para refletir e reforçar o controle colonial (DARBY, 2006).

Não obstante, o próprio futebol pode ser o campo onde são refletidas as ojerizas às metrópoles de outrora. Nesse sentido, observa-se a situação registrada por Vidacs (2004) nos Camarões durante a realização do Mundial de 1998, quando no decorrer de todo o torneio, 
a maioria dos camaroneses estava, explicitamente, torcendo contra os franceses ${ }^{1}$, seus antigos colonizadores. Muitos pesquisadores, como investigado por esta autora, avaliam os esportes na África como uma área onde os habitantes deste continente podem desafiar o status quo da ordem colonial apropriando as formas organizacionais do exterior e aspirando vencer os colonizadores no seu próprio jogo, enquanto que, simultaneamente, produzem novas identidades para si. Mas devido aos penetrantes efeitos da colonização e os contínuos laços neocoloniais que ainda amarram os ex-colonizados aos ex-colonizadores, a relação latente de subordinação se mantém ao passo que são formadas novas distorções.

Este artigo foi elaborado com a intenção de mostrar os usos coloniais e neocoloniais do futebol empreendidos por Portugal e França. Portanto, para melhor compreensão das nossas ideias, primeiro trataremos da situação do futebol durante o período colonial. Neste primeiro tópico, apresentaremos as razões pelas quais as metrópoles utilizaram jogadores oriundos das colônias nas suas seleções metropolitanas e o panorama do futebol nestas localidades. Em seguida, debateremos a conexão entre a metrópole, a colônia e os sujeitos, ou seja, entre o colonizador e o colonizado. Discutiremos como o metropolitano compreendia o colonizado. Qual o estatuto legal dele em Portugal e na França? Em quais momentos isso mudou? E quais os seus desdobramentos? No último tópico, antes das considerações finais, trataremos da situação atual desses "ex-indígenas", os jogadores africanos das ex-colônias e a migração para o futebol das ex-metrópoles, além de traçarmos um breve histórico dessa situação.

\section{O esporte e o colonialismo}

A investigação sobre esporte no período colonialista pelas ciências humanas ainda é recente. Esse campo ainda não possui um lastro teórico-epistemológico quando comparado a outros campos já devidamente estabelecidos. A maior parte das pesquisas que há foi produzida por autores que se debruçaram sobre o caso britânico do uso colonial do esporte como ferramenta do exercício de poder, uma espécie de manutenção da cultura imperialista. De modo a mencionar tais investigadores, destacamos dois: os pesquisadores James Anthony Mangan e Brian Stoddart (apud DOMINGOS, 2006). Mangan cunhou o conceito de teoria de vínculo², que consistiria nos laços culturais criados a partir das práticas esportivas entre colonizador e colonizado. A estrutura de tais laços conduziria a uma melhor aceitação dos valores impostos pelos metropolitanos, o que teria como consequência uma legitimação política. Por sua vez, Stoddart pensa o sistema esportivo colonial como um veículo transmissor de ideias e valores

1 Embora Camarões tenha sido colonizado, inicialmente, pela Alemanha e, após a Primeira Guerra, pela França e Grã-Bretanha, são os franceses que possuem o vínculo mais forte com os camaroneses. Segundo Vidacs (2004), isto se deve, em parte, pelas diferenças nas formas de colonização atreladas ao compromisso na transmissão dos valores culturais franceses aos colonizados, e, no presente, como uma questão de desejo do Estado Francês em manter a primazia da língua francesa na região.

2 Tradução literal de bond theory. 
que auxiliaram na consolidação do poderio da metrópole sobre a colônia. As atividades físicas foram tomando um espírito disciplinador e socializador, gerando instantes de reprodução da condição social naquele momento.

Ao contrário do que muitos poderiam supor, ao futebol não foi dado o estatuto de esportechefe do império britânico porque juntamente com ele também foi disseminado o rúgbi (râguebi) e o críquete, para citar os que mais se destacaram nesse "aspecto lúdico do colonialismo". Ele foi disseminado por soldados, professores, comerciantes, mineiros, trabalhadores de ferrovias, e não através de um corpo diplomático, ou algum outro elemento institucionalizado da Coroa.

Depois desse "pontapéinicial", o esporte foi difundido junto aos grandes empreendimentos públicos e privados que financiavam as práticas esportivas com o intuito de controlar as relações de trabalho. Assim, em Angola, temos o exemplo do Petro Atlético de Luanda, pertencente à Companhia Petrolífera, e o Ferroviário, identificado com a empresa estatal ferroviária. Importante salientar que a difusão dos esportes modernos, como maior exemplo o futebol, ocorreu em um momento de grandes transformações das sociedades africanas, no início do século XX, com alterações drásticas nos sistemas de trabalho, intensos processos de urbanização, controle veemente por parte do Estado sobre o território e os indivíduos, novas práticas nos sistemas familiares e nas hierarquias tradicionais (DOMINGOS, 2006).

Há mais fatos que comprovam a imposição da metrópole sobre a colônia por meio do futebol. Mas o que mais nos chamou a atenção foi o uso de colonizados nas seleções nacionais das metrópoles. Fomos buscar na história como tudo isso começou. Descobrimos que dentre as principais potências coloniais, a que mais cedo se aproveitou do artifício de utilizar um colonizado na seleção da metrópole foi a França, que em 1931 contou com a presença de um negro no mais alto nível internacional. O jogador que abriu as portas foi Raoul Diagne, nascido na Guiana Francesa, de pais senegaleses. Inclusive o seu pai, Blaise Diagne, foi um dos primeiros deputados negros da Assembleia Nacional Francesa representando o território do Senegal. Diagne estreou numa derrota para Tchecoslováquia por 2 a 1, em 15 de fevereiro de 1931 (JACQUES, 2010). Em contraste com a sua rival histórica, a primeira vez que a Inglaterra teve um negro no time principal foi em 1978, quando Viv Anderson, nascido em Nottingham, mas com ascendência jamaicana, entrou em campo na vitória de 1 a 0 contra, curiosamente, a mesma adversária dos franceses, a Tchecoslováquia. (VASILI, 2000).

Opostamente ao que acontece na França, onde ainda persiste um debate público ${ }^{3}$ sobre a participação de jogadores das ex-colônias na seleção nacional. Em Portugal, ao menos, isto aparenta ser velado ou já naturalizado. Essa diferença pode acontecer devido aos distintos "estilos" de serem imaginados franceses e portugueses tanto os de além-mar, quanto os da metrópole, e dos recursos de que se utilizaram para isso. O uso de jogadores africanos na seleção

3 O debate público na França acontece em torno da ascensão no campo político da Frente Nacional, o partido de extrema direita, simultaneamente, aos sucessos da seleção nacional no cenário internacional entre o fim da década de 1990 e início dos anos 2000, sobre a participação dos jogadores das ex-colônias nessa equipe europeia (Cf. VIDACS, 2004). 
das quinas ${ }^{4}$, por exemplo, data de 1937, quando Guilherme Espírito Santo, atleta benfiquista, ajudou na vitória do seu selecionado ante a seleção da Espanha por 2 a 1, em pleno solo espanhol. Espírito Santo nasceu em Lisboa de pais angolanos, mas devido a problemas familiares retornou a Luanda e foi criado lá até os 17 anos (TOVAR, 2011). Desde então, Portugal soube aproveitar esse aspecto das suas colônias ultramarinas da África, tratando o esporte como um instrumento a favor do Estado, o que Nolasco (2012) salienta como o colonialismo ideal. A instrumentalização chegava a ponto da ex-metrópole possuir clubes-satélites na África, exemplo disso é ligação do Benfica lisboeta com o homônimo luandense, e o laço estreito entre o Sporting de Lisboa com o homônimo de Lourenço Marques (atual Maputo) ${ }^{5}$.

A partir de então, a seleção portuguesa se locupletou do sistema colonial convocando jogadores negros nascidos nas províncias ultramarinas. Dentre estes, podemos destacar Matateu, a Oitava Maravilha, moçambicano, que chegou aos Belenenses em 1951 aos 24 anos levado por um ex-jogador dessa equipe, e por lá permaneceu durante 12 temporadas, conquistando uma Taça de Portugal, tornando-se por duas ocasiões o artilheiro do campeonato nacional e pela seleção marcando 13 gols em 27 jogos; Mário Coluna, o Monstro Sagrado, também de Moçambique, aportou no Benfica em 1954 aos 19 anos após ser observado quando jogava pelo Desportivo de Lourenço Marques, foi bicampeão europeu de clubes, levantando 17 troféus nacionais, entre títulos da Primeira Divisão e Taças de Portugal, e pela seleção jogou 57 vezes marcando 8 tentos; e Eusébio, o Pantera Negra, tido como o maior futebolista "português" de todos os tempos, nascido na capital moçambicana.

Reza a lenda que Eusébio, filho de pai branco angolano e mãe negra, iniciou seu percurso esportivo na Europa de maneira confusa. Teve seu local de trabalho incerto, pois não se sabia se iria à Luz, estádio benfiquista, ou ao José Alvalade, "casa” do Sporting. A incerteza só foi sanada após o Benfica, sabendo que a jovem promessa de 17 anos estava destinada aos seus rivais, depois de se destacar na filial sportinguista de Moçambique, ter ludibriado os dirigentes leoninos ${ }^{6}$ e contratado o jovem atleta. $\mathrm{Na} \mathrm{Luz}$, conquistou quase todos os troféus e prêmios que disputou, entre eles estão 16 títulos nacionais e um da Copa dos Campeões Europeus de 1962. Foi eleito no ano de 1965 o melhor jogador da temporada europeia com o prêmio Ballon d'Or, da revista francesa France Football, além de ter marcado 638 gols em 614 jogos ${ }^{7}$ com a indumentária encarnada ${ }^{8}$.

\footnotetext{
4 Uma das alcunhas da seleção de Portugal.

5 Com a independência de Moçambique, o Sporting Clube de Lourenço Marques foi obrigado pelo novo governo a ser renomeado. O novo nome escolhido foi Clube de Desportos do Maxaquene e, por consequência, também mudou suas cores, ao invés do verde e branco optou pelo vermelho e azul.

6 Leonino é uma referência ao leão, mascote do Sporting.

7 As estatísticas referentes aos números de jogos e gols marcados por Eusébio podem ser encontradas em Sport Lisboa e Benfica (2014).

8 Encarnados é uma das alcunhas do Benfica devido à cor vermelha do seu uniforme.
} 
Era muito comum que esses jovens atletas fossem descobertos através de uma relação entre clubes-mãe e clubes-satélite. Tratava-se de verdadeiras filiais esportivas portuguesas no além-mar, já que a partir dessa grande quantidade de sucursais também foi se espalhando o modelo disciplinador da metrópole sobre a colônia. Em Portugal, há três grandes clubes esportivos, dois deles situados na capital e um localizado ao norte, na cidade do Porto. Além do futebol, todos os três possuem equipes em outros esportes, como basquetebol, voleibol, hóquei sobre patins, futsal, etc. Para se ter ideia do tamanho dessa rede colonial esportiva, vejamos o exemplo do Sporting Clube de Portugal, que além da já citada filial da capital moçambicana, teve filiais, casas ou delegações em Luanda (que foi a primeira neste modelo, criada em 1922), São Tomé, Príncipe, Bissau, Praia, Porto Novo, São Vicente, estas três últimas em Cabo Verde; Nampula, Beira, Quelimane, estas três localidades em Moçambique; Benguela, Cabinda, Sá da Bandeira, Namibe (antiga Moçâmedes), Huambo, Sumbe, Silva Porto (atual Kuito) e Malange, todas estas últimas em Angola. O seu rival lisboeta, o Sport Lisboa e Benfica tem (ou teve) representações em Luanda, Bissau, Quelimane, Huambo. Para o Futebol Clube do Porto, as suas filiais se localizam em Angola, nas cidades de Luanda, Cabinda e Uíge; na Guiné-Bissau em Cachungo, Tombali e Bafatá; e em Cabo Verde, em São Vicente ${ }^{9}$. E sequer disfarçavam a ligação, até porque levavam em suas nomenclaturas oficiais os nomes dos "clubes-mãe", muitas das vezes para se aproveitarem da paixão dos torcedores locais pelos clubes portugueses. Além da presença destas representações, havia também a transmissão das partidas das equipas lusitanas através do rádio e excursões delas para a África, um exemplo do papel da imprensa em "alargar" o território português. "Estas práticas, cujos efeitos ultrapassavam o âmbito do futebol, podem ser interpretadas como parte de um plano mais geral da promoção da hegemonia colonial [grifo nosso]" (DARBY, 2006, p. 426).

Foi através dessa rede de prospecção dos melhores jogadores dessas localidades que os três gigantes portugueses foram se abastecendo e, consequentemente, abastecendo a seleção nacional. Confirmava-se, desta forma, a mensagem que o governo ditatorial queria transmitir aos seus cidadãos: a de um amplo território, que se estendia da Europa à Ásia, passando pela África, com uma população unida em torno da mesma bandeira, sem preconceitos entre si, com ordem e disciplina.

O futebol acabou criando um grande paradoxo para a administração colonial, com a instituição do regime do indigenato (como veremos a seguir) e a exploração laboral. Os grandes clubes das metrópoles acabaram por estender essa lógica administrativa para os seus propósitos, e ao contratar os melhores jogadores africanos, eles os tratavam de maneira diferente dos jogadores nativos da metrópole. Como por exemplo, a diferença salarial entre eles, que é testemunhada pelo angolano António Dinis: "I signed a very inexpensive contract with Sporting. I won the National Championship and the Portuguese Cup; I am a member of

9 As pesquisas feitas sobre as localidades dos clubes-satélites foram realizadas através dos sites oficiais dos clubes portugueses (www.sporting.pt; www.slbenfica.pt; www.fcporto.pt). 
the Portuguese national team and, in spite of all this, I had wages that were inferior to the team's reservists"10 (COELHO; PINHEIRO apud CLEVELAND, 2013, p. 31). Os dirigentes esportivos em Portugal estavam bem cientes que os salários oferecidos na Europa eram muito superiores aos disponíveis na África, desse modo, para os jogadores havia pouco espaço para exigências de aumento. Na prática, os jogadores das colônias eram a mão de obra indígena trabalhando na metrópole.

\section{Relações entre metrópole/colônia/sujeito em debate}

O uso dos colonizados nas seleções das metrópoles, conforme descrito no tópico anterior, ocorreu em razão do entendimento legal da submissão destes para com os metropolitanos. Assim foram criados dispositivos jurídicos que os legitimasse. Dessa forma, todos os cidadãos do território, independente da sua localização geográfica, eram considerados pertencentes àquele Estado europeu, mas em "estágios" distintos. Grosso modo, esses estágios eram divididos em: indígena, o nativo negro "selvagem"; assimilados, classe de indivíduos que tinham uma "característica europeia" aos olhos do colonizador; e o metropolitano, que como o nome já nos diz, era o indivíduo branco nascido na Europa. Tudo baseado na concepção, que à época se tinha, do termo civilização, cujas premissas eram a da superioridade da cultura europeia sobre as outras, e ainda, que essas outras só "evoluiriam" a partir do contato com aquela do Velho Continente. Tomando como exemplos os casos de Portugal e França, veremos como cada um entendia os seus cidadãos d'além-mar.

\section{a) $O$ caso português}

Nas terras lusas se tinha o entendimento, a partir da ideia do lusotropicalismo ${ }^{11}$, que Portugal era por natureza uma nação que possuía uma predisposição "diferenciada" das demais na questão da colonização, baseada nos seus empreendimentos mercantil-coloniais anteriores. O que os fatos nos mostram, no entanto, é uma continuação da ideologia colonialista das outras

\footnotetext{
10 "Eu assinei um contrato muito barato com o Sporting. Eu ganhei o campeonato nacional e a Taça de Portugal; eu faço parte da seleção portuguesa e, apesar disso tudo, eu tenho salário que é inferior ao de um reserva da equipe".

11 O lusotropicalismo é uma ideologia elaborada por Gilberto Freyre que trata de uma qualidade de adaptação inata dos portugueses com relação aos trópicos. Essa pretensa aptidão natural adviria da sua plasticidade e miscibilidade congênita, resultado da própria origem étnica híbrida através dos contatos com os mouros e judeus entre a Península Ibérica e o norte da África. Essa ideia foi "abraçada” pelo governo ditatorial de Oliveira Salazar e largamente propagada durante os seus mandatos. Interessante é que tal ideologia se tornou massificada entre a população a tal ponto que mesmo após o fim da ditadura, a esquerda portuguesa teorizou o quasi pertencimento de seu país ao bloco do Terceiro Mundo, algo que permitiu a Portugal alegar sua capacidade de manter ou construir excepcionais conexões não imperialistas com países do Terceiro Mundo, em um tipo de relação Sul-Sul (MORIER-GENOUD; CAHEN, 2012).
} 
potências europeias $^{12}$. A própria transformação dos seus habitantes na África em súditos, administrados por sistemas legais desiguais, cristalizados em categorias rígidas e forçados a processos de assimilação, em razão da suposta impossibilidade da convivência entre estes e os europeus, é uma comprovação da implantação dessa ideologia (SANTOS apud MENESES, 2010).

O termo indígena sintetiza a relação metrópole/colônia/sujeito. É assim que são tratados os nativos da colônia. Os indígenas, segundo o artigo $2^{\circ}$ do Estatuto do Indigenato (FERREIRA; VEIGA, 1957, p. 14) em Portugal, eram identificados como “... os indivíduos de raça negra ou seus descendentes que, tendo nascido ou vivendo habitualmente nelas, não possuam ainda a ilustração e os hábitos individuais e sociais pressupostos para a integral aplicação do direito público e privado dos cidadãos portugueses [grifo nosso]". Criava-se uma situação ambígua para a compreensão desse sujeito, pois ele é nativo do território onde nasceu, um território sob o jugo de um Estado estrangeiro, mas também não é completamente aceito por esse Estado. “Temos assim que os indígenas são súbditos portugueses, submetidos à proteção do Estado português, mas sem fazerem parte da Nação [grifo nosso em negrito], quer esta seja considerada como comunidade cultural (...), quer como associação política dos cidadãos" (CAETANO apud FERREIRA; VEIGA, 1957, p. 13). Este Estado, não se dando por satisfeito, ainda impunha o trabalho forçado para os nativos, que aparece desde 1899 no Regulamento do trabalho indígena. O seu artigo $1^{\circ}$ estabelece que todos os indígenas das províncias portuguesas do além-mar estão sujeitos à obrigação moral e legal de adquirir através do trabalho os meios que lhes faltassem para substituir e melhorar sua condição social. Estes tinham a "liberdade" de escolher a maneira de cumprir tal imposição, o que, caso não fosse feito, poderia lhes ser imposto pelas autoridades (MENESES, 2010).

Importante notar que, mesmo após a instauração da república em Portugal em 1910, a conduta do governo para com suas províncias ultramarinas permaneceu inalterada.

[...] o poder colonial português assentou (...) num conjunto de práticas coercivas que violavam o cerne dos valores democráticos que o novo governo defendia. Os africanos transformaram-se em súbditos indígenas, e não [em] cidadãos; tinham deveres, mas poucos ou nenhuns direitos (MENESES, 2010, p. 77).

O estabelecimento legal da distinção entre portugueses europeus e os "portugueses" africanos se consolida a partir das ideias evolucionistas de Antonio Enes, ministro do ultramar e comissário régio em Moçambique, para quem era totalmente incompatível a incorporação política das populações africanas ao mesmo patamar da cidadania portuguesa; ideia resumida na seguinte assertiva: "Por enquanto, é preciso, nas nossas possessões, a existência de, pelo menos, dois estatutos civis e políticos: um europeu e outro indígena. Não quer isto dizer que seja

12 “... it is true that the economic, financial, military, and political power of Lisbon was inferior to that of London and Paris. But it is a difference of degree, not of nature" (MORIER-GENOUD; CAHEN, 2012, p. 7). 
interdito a todos os indígenas o estatuto europeu, mas isso depende da sua instrução e dos seus hábitos" (COSTA apud MENESES, 2010, p. 79). Justificava-se então, a elaboração de um estatuto específico para os colonizados na África. Entre esses dois continentes distintos nas suas diversas formas, mas simultaneamente interdependentes, ser europeu ou africano (indígena), no espaço colonial português, tornaram-se categorias que mantinham estatutos específicos para cada um.

O dispositivo legal que vai condensar toda essa ideologia colonial, baseada na distinção e submissão entre colonizador e colonizado, é o Estatuto do Indigenato, cuja primeira publicação data de 1926 e a última de 1954 . Obviamente que antes desse estatuto havia uma série de leis e decretos que regulamentavam diversos elementos que compunham toda a estrutura colonial do governo português. Mas é no estatuto que se encontra todo o refinamento da lógica colonial portuguesa sustentada por um arcabouço legal dessa nova categoria inventada, na qual se encontravam os direitos e (muito mais) deveres dos indivíduos em solo africano, dentre os quais, estava instituído o elemento do trabalho forçado. Como vemos, o estatuto é, também, reflexo da contradição do pretenso empreendimento civilizatório e da exigência da ordem colonial, que se mostra patente com a criação da categoria indígena, algo totalmente contrário aos ideais dos novos tempos da Lusitânia republicana.

\section{b) $O$ caso francês}

A França, assim como Portugal, entendia o nativo como indígena. Para normatizá-lo também elaborou o seu dispositivo legal: o Code de l'indigènat, que toma forma a partir da invasão francesa à Argélia na década de 1830 e se torna institucionalizado para as demais colônias em 1881. O regime não foi pensado como um sistema perene na lei que o criou inicialmente, prevendo-se uma duração de sete anos como um regime transitório, marcando uma etapa julgada como "necessária para a evolução" de um país em via de pacificação. No entanto, como a história nos mostra, o "código" do indigenato permaneceu vigente até a primeira metade do século XX.

Uma das coisas que mais surpreendem nesse regime é a ruptura causada no direito republicano francês. Tratava-se de um espaço jurídico novo, exclusivamente reservado aos nativos das colônias para os quais são criados os delitos e as penas inexistentes ou inaplicáveis no contexto metropolitano. Tal desrespeito às premissas do direito francês consistia, por exemplo: no exercício da autoridade administrativa como poder judiciário, na permissão às punições coletivas, nas deportações, na punição de práticas que a lei metropolitana não proibia e a interdição à defesa e à possibilidade de apelação. Certos delitos e penas eram baseados em situações excepcionais ocorridas em tempos de guerra, enquanto outros faziam parte do controle de proximidade em situação colonial, como a ofensa à autoridade e ao prestígio do colonizador, e a proibição de costumes locais como a magia e a nudez (MERLE, 2004). 
As arbitrariedades eram inúmeras. As infrações concernem desde regras de higiene, como enterro de animais e recusa de vacinação, passando por normas de urbanismo, como construções ilegais, reunião sem autorização, saída do território da comuna sem permissão, recusa em aceitar a moeda francesa, até as questões que envolvessem a "boa ordem colonial". Por boa ordem colonial entendiam-se as interdições às manifestações de resistência, à greve, às recusas de trabalho forçado e ao pagamento de impostos. As penas compreendem multas e aprisionamento por até quinze dias, embora as multas pudessem ser convertidas em dias de prisão; estas podiam ser cobradas até coletivamente, quando os indivíduos não eram identificados. Além disso, há alguns relatos em que a punição aplicada era o castigo corporal, mesmo sendo este ilegal (MERLE, 2004).

É com esse dispositivo legal que o governo francês, com a anuência dos líderes nativos, obriga o trabalho forçado aos negros, seja para utilização em obras públicas ou privadas. $\mathrm{O}$ pesquisador Babacar Fall (1993) distingue cinco modalidades de trabalho forçado na África Ocidental Francesa $(\mathrm{AOF})^{13}$ : a principal de todas era o recrutamento da mão de obra, forma coercitiva mais antiga usada, que baseava-se na pressão, intimidação e repressão exercidas pelos guardas dos cercles $^{14}$ e agentes recrutadores; a prestação, que era uma requisição aos contribuintes, que além do pagamento de impostos, prestavam uma quantidade definida de dias de trabalho em "benefício" das obras públicas de interesse local; a segunda porção do contingente militar, que consistia em utilizar a lei militar obrigatória convocando os homens a servir o exército e aproveitando-se da parcela sobressalente determinando a utilização destes para as obras púbicas; a mão de obra penal, formada pelos prisioneiros para a utilização em diferentes obras, desde construção de caminhos de sirga, manutenção dos cais e vias urbanas, até as reparações nos edifícios administrativos; e, por último, a obrigação de cultivar, pois para os teóricos da colonização, já que os africanos possuíam uma agricultura muito "primitiva", a metrópole deveria impor certas culturas mais industrializadas com o objetivo de "educá-los".

Embora seja conhecido como um code, a legislação referente ao indigenato não era formada por uma compilação unificada de textos jurídicos como o código civil ou penal. Por isso alguns especialistas em direito colonial preferem chamá-lo de regime para qualificar uma série de regulamentações esparsas, específicas em cada colônia encontradas de modo heterogêneo, sob formas variadas, de maneira total ou parcial (MERLE, 2004).

O regime do indigenato nas colônias francesas cobre, portanto, um nível duplo de repressão. O primeiro, exercido pelo governo, diz respeito aos atos graves ou julgados como tal colocando em "perigo a segurança pública”. Sendo que não havia nenhuma lista previamente definida desses atos considerados graves, o que deixa aos administradores locais uma larga margem de "flexibilização" (MERLE, 2004). E o segundo, dessa vez de uma maneira localizada, se dá em razão da vigilância

13 Região que reunia em uma mesma federação oito territórios durando de 1895 até 1958, sendo formada pelos seguintes países: Mauritânia, Senegal, Mali, Guiné-Conacri, Costa do Marfim, Níger, Burkina Faso, Togo e Benim. 14 Cercle é a menor unidade administrativa nas colônias francesas na África dirigida por um metropolitano. 
cotidiana que os colonizados sofriam. Pois, através dos tipos de infrações especiais se encontram acionados o exercício de uma dominação total que não se exerce somente na ordem objetiva das práticas, mas também na ordem simbólica, na transmissão aos nativos dos signos ostentatórios do respeito ao "prestígio do colonizador" (SAADA apud MERLE, 2004).

Portanto, como podemos notar, o regime do indigenato, tanto em Portugal quanto na França, tratava-se de um sistema que não era apenas um instrumento de dominação simples, mas era também uma regulação da violência legal, uma violência exercida e patrocinada pelo Estado aux enfants de la Patrie considerados de "segunda e terceira categoria". Observa-se, portanto, que por trás da "intenção civilizatória” da metrópole, encontravam-se os mecanismos objetivos e subjetivos para submeter às colônias as vontades da metrópole.

Os próprios Estados faziam questão de dividir suas respectivas "populações" entre indígenas, assimilados e cidadãos. Como acima referido, o indígena africano, além de ser considerado alguém de segunda classe, era submetido a trabalhos forçados, basicamente braçais, em profissões com baixa remuneração, sem acesso à educação, sujeitos à violência física e às arbitrariedades jurídicas. Ou seja, ele não vive uma vida autônoma e sim uma vida sofrida. Não obstante, para os não indígenas, os europeus que viviam na África e seus descendentes, a situação era diferente, pois tinham os mesmos direitos do europeu que vivia na metrópole (MENESES, 2010).

De acordo com Anderson (2008), o uso do termo indígena para as populações colonizadas sempre tinha uma carga semântica paradoxal, involuntariamente. Significava que as pessoas assim denominadas eram "inferiores" e, também, pertenciam a uma nação europeia, simultaneamente. A construção do sujeito colonial e do exercício do poder, ambos no discurso, demanda uma articulação das diferenças. A articulação é fundamental para considerarmos o corpo, que é a ferramenta de trabalho do jogador de futebol, como inscrito, ao mesmo tempo, na economia do lazer (leasure) e da aspiração (aspire $)^{15}$ bem como nas economias do discurso, da dominação e do poder (BHABHA, 2007).

Assim sendo, a principal semelhança entre as concepções colonialistas dos Estados Francês e Português é a questão dos assimilados, que se tratava de um processo "europeizante" de determinados indivíduos, cujo objetivo era a formação de uma pequena elite de negros privilegiados que colaborassem com a colonização. Para o indivíduo sair da categoria indígena para a de assimilado, ele teria que, genericamente, cumprir alguns requisitos, como: falar corretamente o idioma da metrópole, possuir uma profissão que lhe desse o rendimento necessário para si mesmo e família, ter uma boa conduta social, praticar costumes considerados europeus ${ }^{16}$ e ter cumprido suas obrigações com o serviço militar.

15 Aqui tomamos a liberdade de modificar um pouco a leitura de Bhabha (2007) sobre essa questão. O pensador indiano escreve na sua obra original os termos pleasure (prazer) e desire (desejo), no entanto, para o trabalho aqui proposto reutilizamos as formas etimológicas dos sufixos das referidas palavras.

16 No caso português, isto significava, entre outros elementos, professar a fé católica. 
Segundo Bhabha (2007), o objetivo do discurso colonial é apresentar as populações colonizadas como pessoas necessitadas daquele modelo de administração, com base na distinção racial, com o fim de justificar a conquista e o estabelecimento do modelo metropolitano de condução da vida social. Tal modelo de condução, ao disciplinar o território subjugado, apropria e domina quase todas as esferas da atividade social, incluídos aí os esportes. Assim, o discurso colonial produz um tipo de colonizado que é um "outro" e ainda assim inteiramente apreensível e visível.

Levando em conta a análise de Anderson (2008), podemos acreditar que essa "extensão do território" era auxiliada pelo uso em comum do mesmo idioma, uma imposição da metrópole, e também por causa do papel fundamental desempenhado por uma mesma imprensa que percorria todos os pontos importantes do Império. Ou seja, ela acompanhava os fatos de Lisboa e Paris e seguiam os acontecimentos de Luanda, Dacar, Bissau, Conacri, Abidjan, São Tomé, etc., por exemplo. É a noção da simultaneidade que construía solidariedades particulares. Um exemplo desta solidariedade específica é a torcida, nas antigas colônias portuguesas em especial, da maioria dos nativos pelas equipes da metrópole, pois como constatado em Moçambique, mesmo vinte anos após a independência somente $15 \%$ da população preferia as equipes locais às equipes portuguesas (BBC apud DARBY, 2006). Também havia a exportação dos jornais da metrópole, pois se imagina que o colono europeu que estivesse em alguma "província ultramarina" tivesse mais interesse pelas notícias de Paris, de Lisboa, de Marselha e do Porto, do que pelas de Argel, Lourenço Marques, Lomé e Benguela, por exemplo. Até os dias atuais podemos ver correspondentes e sucursais de jornais portugueses e franceses nessas localidades, registrando os fatos e reportando às matrizes como se ainda estivessem no período colonial, atrelado ao fato de que a procura agora é também dos imigrantes africanos que estão na Europa.

A extensão territorial também ocorria através do sistema educacional da colônia, pois para as crianças da África portuguesa e francesa também eram ensinadas as "histórias nacionais" das respectivas metrópoles e seus fatos relevantes para o mundo. Imaginava-se uma "naturalidade" para uma nação que, na maioria das vezes, era uma seleção daquilo que era "nacional" e do que não era. O próprio período salazarista foi mestre em criar esse aspecto "pan-lusitano", até porque tinha como um de seus sustentáculos governamentais o exercício público do nacionalismo. Não é à toa que o mesmo instituiu como o feriado nacional a data de 10 de junho, referente ao Dia de Camões, de Portugal e da Raça, este último termo, como exultação da "etnicidade" portuguesa. O Estado luso sempre se valeu dos desfiles das forças armadas em todas as suas possessões, com o objetivo de demonstrar a nation-ness portuguesa, já que esta é "o valor de maior legitimidade universal na vida política dos nossos tempos" (ANDERSON, 2008, p. 28).

Como Anderson (2008) escreveu, as nações são imaginadas, já que fazem sentido para a "alma" e constituem objetos de desejos e projeções. Imaginadas no sentido dos cidadãos de uma mesma localidade terem em mente a imagem de uma mesma sociedade nacional, de um mesmo governo único e impessoal, tendo algum tipo de conexão, mesmo que involuntária. No entanto, 
sabemos que todos esses cidadãos nunca irão se encontrar face a face. Uma nação que comparada a um organismo sociológico, que perpassa um tempo cronologicamente vazio e homogêneo, é uma espécie de comunidade sólida percorrendo a história, seja no sentido descendente ou ascendente. O que tornou palpável a possibilidade de imaginar novas comunidades foi a dinâmica entre o capitalismo, com seus novos modos e relações de produção, com o inovador papel da imprensa e a diversidade linguística do ser humano.

No caso específico dos Estados coloniais, o autor de Comunidades Imaginadas (2008) demonstra, no penúltimo capítulo da sua obra, que três instituições foram fundamentais na construção das imaginações nacionais: o censo, o mapa e o museu. Tais elementos aliados pensaram o modo como a metrópole encarava seu domínio ultramarino. Criando realidades unificadas, por mais diferentes que pudessem ser, instituíram suas próprias categorias raciais, histórias lógicas e sequenciais, mapas e fronteiras estabelecidas.

Os censos, mais que espelhar, construíram realidades claras e rígidas, permitindo prever políticas para essas populações devidamente imaginadas. Os mapas estabeleceram limites, demarcaram espaços e constituíram um novo discurso cartográfico capaz de comprovar a vetustez das unidades territoriais. Por fim, não se pode descurar da importância da imaginação museológica e dos serviços arqueológicos coloniais que se conformaram como instituições de poder e de prestígio (SCHWARCZ, 2008, p. 15).

A imaginação colonial se dava, também, através dos edifícios que se transformaram em monumentos, as histórias próprias que foram elevadas ao patamar de nacional. E então encontramos a trama fundamental desse pensamento totalizante e classificatório, ressignificando, quase que instantaneamente, datas em eventos públicos, fatos elocais em marcos da nacionalidade, tudo isto com tamanha flexibilidade, sempre com a chancela do Estado. Observa-se que, no que tange ao idioma da metrópole, ainda há simultaneidade de falantes de outros dialetos locais, criando situações em que o idioma europeu é falado fluentemente apenas por uma parcela da população e utilizado como a língua franca para a compreensão comum entre dialetos distintos.

Talvez tenha sido a partir desse entendimento de cidadãos “compatriotas" de várias partes do globo, mas participando de um mesmo universo cultural, como se todos estivessem num único amplo território sob o mesmo governo, que tenha surgido um espaço social autônomo de migração. Essa pretensa facilidade de adaptação à ex-metrópole seduz todos os anos cada vez mais os nativos das ex-colônias. Por espaço autônomo de migração entendemos, a partir do que foi explicado por Morier-Genoud e Cahen (2012), que são espaços estruturados, originalmente, a partir das sociedades metropolitanas, mas que se tornaram autônomos da metrópole e se ampliaram além do espaço político, cujo movimento acontece à demanda do Estado e/ou de grandes companhias privadas. 


\section{As relações neocoloniais}

Após os conflitos que se seguiram pela luta da independência das colônias africanas, no pós-Segunda Guerra, as políticas de construção de Estado dos recém-libertados territórios se tornaram com frequência um verdadeiro entusiasmo de nacionalismo popular. Some-se a isso a instigação sistemática da nova ideologia nacionalista, através dos meios de comunicação de massa, como do rádio e do jornal e, sobretudo, por meio do sistema educacional e das novas normas administrativas que foram levadas a cabo da noite para o dia assim que estes países conseguiram sua autonomia política (ANDERSON, 2008).

De fato, essa mistura dos novos nacionalismos, tanto por parte oficial quanto por iniciativa particular, foi o corolário das anomalias criadas pelo imperialismo europeu. Exemplos disso são a definição arbitrária das fronteiras e a imposição frágil da elite intelectual bilíngue sobre as populações monoglotas (ANDERSON, 2008). Isto resultou, contemporaneamente, em projetos de Estados-Nações ainda inconclusos que estão se solidificando no cenário das relações internacionais. Interessante notar a equivalência que há entre a extensão territorial com os novos nacionalismos, o que vai ser indicado no uso do contorno do mapa como um dos emblemas nacionais, que exemplifica a materialidade do nascente nacionalismo, o mapalogo imediatamente identificável e singular nos brasões de armas na pós-independência. Como exemplo, nesse sentido, há os casos de Moçambique, que tem o contorno do mapa olhado a partir do Oceano Índico, dos Camarões e de Madagascar, simbolizando um processo de mudança de um Estado colonial para um Estado nacional singular e independente.

No entanto, mesmo após as independências dessas nações e possuídas por todo esse furor nacionalista, as ex-colônias continuaram a manter um vínculo direto e indireto com as antigas metrópoles. $\mathrm{O}$ vínculo direto se mostra nos acordos sociocomercias, como o Acordo de Cotonou $^{17}$, a Francofonia ${ }^{18}$ e a CPLP ${ }^{19}$, por exemplo; o indireto, ou não formal, se apresenta nas intenções particulares explícitas ou não dos cidadãos dos países inseridas na relação que uma vez foi metrópole-colônia.

Tomando os nossos casos em questão como exemplo, a relação neocolonial entre Portugal, França e suas ex-colônias no futebol se mostra em fluxo frequente. Portugal, por exemplo, continua sendo um dos principais destinos de jogadores africanos, sendo a maioria destes oriundos da África lusófona, correspondente a 65\% (DARBY, 2006). Não nos esqueçamos de que foi o mesmo Portugal pioneiro no uso de mão de obra escrava negra em 1510. Os agentes

17 Trata-se de um acordo entre a União Europeia e países da África, Caribe e do Pacífico (ACP), que tem como objetivo, a redução da pobreza, a contribuição ao desenvolvimento sustentável e a gradual integração dos países da ACP na economia mundial.

18 A Organização Internacional da Francofonia (OIF) é uma entidade que reúne países cuja língua oficial é a francesa. Seus objetivos são a promoção do idioma francês, da paz e dos direitos humanos, o apoio à educação e à pesquisa científica, e a cooperação para o desenvolvimento sustentável.

19 CPLP é a sigla para a Comunidade dos Países de Língua Portuguesa, entidade com os mesmos propósitos da Francofonia para os países de língua portuguesa. 
dos jogadores e dirigentes de clubes utilizam-se do artifício de que a melhor porta de entrada para a Europa para esses jovens imigrantes é através de Portugal, entre outras coisas, em razão do uso do mesmo idioma. Isso é uma forma patente de exploração neocolonial da antiga metrópole, pois como salienta Darby (2006, p. 427),

[...] esta estratégia pode ser comparada às práticas imperialistas e neo-imperialistas de exploração económica, no sentido em que envolve a localização, [prévio] refinamento e exportação de matérias-primas - neste caso, o talento futebolístico - destinadas ao consumo no mercado europeu.

Ou seja, além de ter sugado quase todos os recursos naturais e matérias-primas baratas no passado (e ainda no presente), encontraram no futebol mais uma modalidade para exercer sua força neocolonial.

As migrações de jogadores de futebol também contribuíam para um mais amplo poder de influência cultural portuguesa e francesa. Entre as décadas de 1950 e 1960, as potências europeias se utilizaram dessa prerrogativa "utilitarista", as conexões entre ex-metrópole e excolônia, tornando-se cada vez mais frequente o fluxo migratório dos jogadores africanos à Europa, sendo que os três principais destinos são ex-metrópoles: na ordem, França, Bélgica e Portugal (DARBY, 2006).

Nesse mesmo período, o futebol francês, por exemplo, começa a ser preenchido cada vez mais por jogadores do oeste africano, que vão, por sua vez, tomando o espaço dos norteafricanos ${ }^{20}$, tendo como seus precursores o beninês René Gaulon, meia do Stade Français, o marfinense Jean Tokpa, atacante do Montpellier, e o camaronês Eugène N’Jo Léa ${ }^{21}$, atacante do Saint-Étienne, ainda na década de 1950. Curioso notar que os primeiros negros que aportaram para jogar na França eram associados na imprensa ao campo semântico do extraordinário, do fenomenal, do misterioso. Eles eram denominados como "os diabos", "os magos", "os bruxos", "as pérolas", "os terrores", "os maravilhosos" (BOLI, 2010a; 2010b).

É com a chegada do malinês Salif Keïta em 1967 ao Saint-Étienne, e o seu retumbante sucesso, que se modifica a percepção sobre os jogadores africanos na França e, logo, cria-se o

$20 \mathrm{Na}$ temporada 1963-64, a quantidade de jogadores da África Subsaariana ultrapassa aqueles provenientes da região do Magrebe, 23 contra 22 (BOLI, 2010b).

21 A história de vida de N’Jo Léa é muito curiosa e inversa ao que são, atualmente, as histórias dos jogadores imigrantes, pois durante toda a sua carreira no futebol concomitantemente manteve-se ligado aos estudos. Ele vai para a França em razão de uma bolsa de estudos secundarista, ao chegar lá, joga por diversão pelo modesto time do Roche-la-Molière destacando-se, ao marcar 11 dos 12 gols de sua equipe. Assim, o camaronês desperta a atenção do grande clube da região, o Saint-Étienne, que o contrata em 1954 e lá passa os cinco anos seguintes. O atacante sai dessa equipe em razão da cidade stéphanoise não possuir uma universidade, logo ele se transfere à Lyon para jogar pela equipe local e iniciar seus estudos superiores na faculdade de Direito. Após dois anos nessa cidade, ele obtém o diploma e decide fazer uma pós-graduação. Novamente, ele muda de clube, e vai atuar na capital francesa, pelo Racing, cuja estadia durou apenas uma temporada. Em seguida, após a finalização dos seus estudos, ele se torna um diplomata estagiário em Roma, cuja ocupação não era possível conciliar com a de jogador de futebol, em razão disso, o camaronês opta por abandonar o mundo da bola (BARREAUD, 1997). 
interesse mais acentuado por eles. A imprensa exaltada o classificou entre os melhores jogadores do mundo naquele momento, que eram Pelé e Eusébio. Logo no ano seguinte à sua chegada, o "estrela negra" torna-se o primeiro negro a ser eleito o melhor jogador estrangeiro da França. O seu sucesso vai além das quatro linhas; ainda em 1968, em razão da atenção despertada sobre os jogadores do continente negro, a France Football22 lança a sua edição africana. Para ela, existiam dois propósitos: o primeiro, de permitir aos africanos conhecerem melhor o futebol do próprio continente e, assim, mensurar o seu progresso esportivo; e o segundo, o de transmitir as notícias, também, aos africanos instalados na França (BOLI, 2010b).

Desde então, as ex-metrópoles permanecem sendo os principais destinos dos excolonizados. Segundo dados apurados por Ricci (apud BALE, 2004), são inúmeros os casos que comprovam a perdurabilidade dessa situação. Por exemplo, a maioria dos jogadores argelinos está na França, assim como três quartos de jogadores emigrados do Senegal, a metade dos futebolistas marfinenses e um terço de atletas camaroneses; no caso lusófono, direcionam-se para Portugal mais de 93\% dos jogadores angolanos.

Como forma de aferir dados quantitativos que constatem essa presença de imigrantes no futebol nesta temporada, levamos em conta as duas primeiras divisões de Portugal e da França. $\mathrm{Na}$ terra lusa, a presença dos africanos lusófonos e descendentes nas camadas superiores da pirâmide do futebol representa praticamente $10 \%$ em cada uma das divisões. Já na França, a porcentagem dos africanos francófonos ${ }^{23}$ e descendentes é maior do que os seus congêneres lusófonos. Eles representam cerca de $40 \%$, na primeira divisão, e $47 \%$ na divisão abaixo ${ }^{24}$. Lembramos que a maior presença dos africanos das ex-colônias se encontra nas divisões inferiores, a terceira em diante ${ }^{25}$, onde o futebol é praticamente amador, o que exige dos clubes um investimento bem menor aos das duas primeiras divisões e regulamentações mais frouxas para inscrição de atletas.

É até compreensível essa diferença encontrada entre os países aqui estudados, pois, enquanto a França possuía o que hoje corresponde a 20 Estados-Nações na África, além dos protetorados no Caribe; Portugal dominava "apenas" 5 no continente negro. Ou seja, um país colonizava quatro vezes mais territórios do que o outro e essa disparidade acaba sendo refletida na porcentagem da quantidade de ex-colonizados e seus descendentes nas ex-metrópoles. Tal porcentagem é explicada também porque as equipes francesas se valem da regra que os jogadores provenientes de países signatários do Acordo de Cotonou não são contabilizados

22 Trata-se da revista esportiva mais prestigiosa da França, criada em 1946, que tem uma periodicidade semanal. 23 Excluímos desta contabilidade os africanos oriundos do Congo - Kinshasa, que apesar de ser um país francófono foi colonizado pela Bélgica.

24 Tais porcentagens foram calculadas a partir das relações de jogadores inscritos em cada divisão através das informações disponibilizadas nos sites http://www.zerozero.pt e http://www.leballonrond.fr. A escolha destes sites se dá em razão do fato de que são locais que atualizam os planteis de cada equipe regularmente.

25 Os dados apresentados por Bale (2004) apontam que 54\% dos jogadores africanos que estão na França jogam nas divisões mais baixas, e em Portugal essa mesma situação é representada por 56\%. 
como estrangeiros pela liga francesa. Portanto, os clubes franceses se aproveitam de um tratado neocolonial, o qual inicialmente surgiu como proposta da União Europeia para ajudar a redução da pobreza dos países signatários da África, do Caribe e da região do Pacífico para melhorar seus planteis a um custo muito mais baixo do que se fossem buscar estrangeiros em outras localidades.

Tanto no caso português, como no caso francês, esse aliciamento dos jogadores provenientes das ex-colônias por parte dos clubes se dá por dois motivos patentes, pelo menos: primeiro, pelo preço de contratação que é inferior quando comparado com jogadores de outras localidades; e segundo, pela (suposta) herança cultural comum, o uso do mesmo idioma, um pretenso comportamento homogêneo que já seria conhecido pela ex-metrópole. Geralmente, tal aliciamento ocorre em razão de uma verdadeira rede criada entre os clubes dos dois continentes por uma personalidade africana de prestígio no clube europeu. Ademais, entre as motivações do migrante, está o aspecto econômico, que é sempre determinante, mas também, o desejo de fazer da sua paixão seu ofício e assim modificar o seu destino social de precariedade. Através do ofício de futebolista, o indivíduo pode transformar não apenas sua vida, bem como a de vários membros da família (BOLI, 2010b).

Além disso, durante a pesquisa destes dados descobrimos casos de angolanos, caboverdianos e guineenses de Bissau que decidem "tentar a vida” profissional no futebol na França, sem passar por Portugal. Isto nos mostra que, atualmente, não há uma parada obrigatória na Terra de Camões. Ao contrário do que ocorria antes, como foi constatado num depoimento de Eusébio: "To become professionals we had to go to Portugal"26 (ARMSTRONG, 2004, p. 255). Essa escolha se dá, provavelmente, em decorrência de que na França o salário pago seja maior ${ }^{27}$ e das condições estruturais de trabalho mais desenvolvidas.

A utilização desse recurso neocolonial nas ligas domésticas acaba auxiliando as seleções nacionais europeias, pois em razão da atribuição da dupla nacionalidade facilita-se a convocação desses jogadores. Fizemos uma rápida pesquisa e constatamos que em todas as participações de Portugal nos Mundiais de futebol (1966, 1986, 2002, 2006, 2010, 2014), a seleção das quinas contou com ao menos um luso-africano, exceto quando de sua participação no México, em 1986, embora Rui Jordão, angolano, tenha contribuído para o desenvolvimento dessa equipe mundialista durante as Eliminatórias para aquela Copa e também na Euro ${ }^{28}$ de 1984. Na primeira dessas participações, na Inglaterra, em 1966, a equipe contou com quatro luso-africanos dentre os 22 convocados: Vicente Lucas, Eusébio, Mário Coluna e Hilário, todos moçambicanos. Em 2002, contou com a participação do Abel Xavier, também oriundo de Moçambique. Em 2006, estiveram presentes Costinha, de ascendência angolana; Miguel, de ascendência guineense; e Luís

26 "Para tornar-nos profissionais, nós tínhamos que ir para Portugal".

27 Enquanto o salário médio dos jogadores da primeira divisão portuguesa era $£ 21.291$ mensais, na correspondente francesa, a média era de $£ 82.327 /$ mês (HARRIS, 2004).

28 Euro é abreviação para Campeonato Europeu de Futebol, também conhecido no Brasil como Eurocopa. 
Boa Morte, de ascendência cabo-verdiana. Em 2010, foram convocados: Rolando, nascido em Cabo Verde, e Miguel, que novamente foi convocado; além de três brasileiros, o alagoano Pepe, o baiano Liédson e o paulista Deco, cuja participação não afeta propriamente esta discussão, mas revela a importância e o peso da presença dos estrangeiros lusófonos nessa seleção. Em 2014, os representantes dessa categoria foram William Carvalho, de Angola; Éder, da GuinéBissau; Nani e Silvestre Varela, de Cabo Verde.

Na seleção francesa, o caso de jogadores africanos nos mundiais também é recorrente. A utilização de jogadores magrebinos é anterior a dos jogadores negros, pois temos o caso de Villaplane, em 1930, e Alcazar, em 1934. Mas, a partir da Copa de 1938, há a concomitância das duas regiões africanas na seleção, com as convocações de Diagne, Ben Bouali, Bastien e Brusseaux, o primeiro de ascendência senegalesa e os outros argelinos. Desde então, em todas as Copas do Mundo que Les Bleus participaram, há a inclusão de jogadores das ex-colônias e dos territórios ultramarinos, seja da África ou das Antilhas. Como constatação, na última Copa do Mundo realizada em 2014, dos 23 selecionados, 8 eram nascidos ou tinham ascendência nessas localidades: Evra, Sagna e Sakho, do Senegal; Varane e Rémy, da Martinica; Benzema, da Argélia; Sissoko, do Mali; Pogba, da Guiné-Conacri.

\section{Considerações finais}

Depois de tudo isso que aqui levantamos acerca do debate em torno dos temas sobre colonialismo, nacionalismo e futebol, como a prática cultural intermediária desses fenômenos sociais, convém levar em conta as novas formas do colonialismo ou, segundo alguns, o neocolonialismo, que aparece nos moldes do contínuo exercício da força econômica das equipes europeias sobre as equipes africanas. Não se pode, no entanto, esperar outra atitude por parte das equipes do continente negro, já que a dependência comercial da venda de jogadores é patente, o que acaba contribuindo de maneira a empobrecer tecnicamente e desacelerar o desenvolvimento das mesmas devido aos termos e condições impostos verticalmente. Curioso que Portugal, antes o destino final dos jogadores afro-lusófonos, agora é considerado o destino intermediário, que serve àqueles como um stage ("estágio") antes de alguns deles atuarem nos melhores stages ("palcos") da Europa. Como bem observou Boaventura de Sousa Santos, "Portugal [é] como [um] mediador entre o centro e a periferia" (apud RIBEIRO, 2003, p. 3).

Como podemos notar, o futebol ainda é um meio de mobilidade social, maneira pela qual a sociedade se integrava, chegando a ser, para alguns afortunados por esse talento, um modo de se chegar até a metrópole. Era um dos poucos casos em que era concedido espaço e visibilidade aos africanos. Neste esporte, podemos fazer uma associação do que ocorre com a África ainda na contemporaneidade, pois a matéria-prima bruta é africana, mas a produção final é europeia. É lá que os atletas são "lapidados", as "pérolas brutas" são levadas cada vez mais cedo. Os jovens atletas são cooptados pelos centros de treinamento de futebol juvenil financiados por 
equipes europeias nos Camarões, no Senegal, na Costa do Marfim, que ali se instalaram a partir da década de 1990, cujo objetivo é alimentar os clubes financiadores (BOLI, 2010b). Ou seja, constata-se, estritamente, uma produção tipo exportação.

No fundo, há que se observar que apesar do surgimento dos Estados nacionais na África portuguesa, é ainda pela língua de Camões que tanto Angola, quanto Moçambique, GuinéBissau, Cabo Verde e São Tomé e Príncipe, são imaginadas e se comunicam com o mundo externo. O mesmo pode-se dizer da África francesa, onde os dialetos crioulos também são reservados para as relações sociais internas apenas. Isso significa que, apesar da independência política ter sido conquistada, mesmo que através de manchas de sangue, ainda há, queiram ou não, uma certa dependência cultural, e, em alguns setores, econômica, como no caso específico do futebol, desses países africanos para com a antiga metrópole. "Uma vez colônia, (quase) sempre colônia”. Esta frase significa que para uma ex-colônia, que se tornou independente no século XX, a descolonização é um diálogo intermitente com o passado colonial. Isto é, um diálogo que sofreu uma interrupção apenas momentânea, mas que aparece na vida social em situações significativas.

\section{Referências}

ANDERSON, Benedict. Comunidades imaginadas: reflexões sobre a origem e a difusão do nacionalismo. 2.ed. São Paulo: Companhia das Letras, 2008.

ARMSTRONG, Gary. The migration of the Black Panther: an interview with Eusébio of Mozambique and Portugal. In: ARMSTRONG, Gary; GIULIANOTTI, Richard (Orgs.). Football in Africa: conflict, conciliation and community. Basingstoke: Palgrave Macmillan, 2004.

BALE, John. Three geographies of African footballer migration: patterns, problems and postcoloniality. In: ARMSTRONG, Gary; GIULIANOTTI, Richard (Orgs.). Football in Africa: conflict, conciliation and community. Basingstoke: Palgrave Macmillan, 2004.

BARREAUD, Marc. Dictionnaire des footballeurs étrangers du championnat professionel français (19321997). Paris : l'Harmattan, 1997.

BHABHA, Homi K. O local da cultura. 5.ed. Belo Horizonte: Ed. UFMG, 2007.

BOLI, Claude. La perception des joueurs africains en France : projection et imaginaire colonial. Hommes et migrations - Revue française de référence sur le dynamiques migratoires, Paris, s/v., n. 1285, 2010a. Disponível em $<$ http://hommesmigrations.revues.org/pdf/1188>. Acesso em 26 nov. 2016.

Les footballeurs noirs africains en France: des années cinquante à nos jours. Hommes et migrations Revue française de référence sur le dynamiques migratoires, Paris, s/v., n. 1285, 2010b. Disponível em <http:// hommesmigrations.revues.org/pdf/1173>. Acesso em 26 nov. 2016.

CLEVELAND, Todd. Following the ball: African soccer players, labor strategies and emigration across the Portuguese colonial empire, 1949-1975. Cadernos de Estudos Africanos, Lisboa, n. 26, dez. 2013. Disponível em $<$ http://www.scielo.mec.pt/scielo.php?script=sci_arttext\&pid=S1645-37942013000200002\&lng=pt\&nrm=iso $>$. Acesso em 04 jan. 2017. 
DARBY, Paul. Migração para Portugal de jogadores de futebol africanos: recurso colonial e neocolonial. Análise Social, Lisboa, v. 41, n. 179, 2006. Disponível em <http://analisesocial.ics.ul.pt/documentos/1218721687I4bIK7nc2Cd19RE4.pdf>. Acesso em 10 nov. 2016.

DOMINGOS, Nuno. Futebol e colonialismo, dominação e apropriação: sobre o caso moçambicano. Análise Social, Lisboa, v. 41, n. 179, 2006. Disponível em <http://analisesocial.ics.ul.pt/documentos/1218721655B5jHL2dx8Yi23BI5.pdf>. Acesso em 10 nov. 2016.

FALL, Babacar. Le travail force en Afrique occidentale française (1900-1946). Civilisations, Bruxelas, s/v., n. 41, 1993. Disponível em <http://civilisations.revues.org/pdf/1717>. Acesso em 26 nov. 2016.

FERREIRA, José Carlos N.; VEIGA, Vasco Soares da. Estatuto dos indígenas portugueses das províncias da Guiné, Angola e Moçambique. 2. ed. Lisboa: s.n., 1957.

HARRIS, Nick. Premier League wages dwarf those around Europe with top-flight players in England earning an average of $£ 2.3$ million a year... almost 60 per cent more than in Germany. Daily Mail, Londres, 14 novembro 2014. Disponível em: <http://www.dailymail.co.uk/sport/football/article-2833020/Premier-League-wages-dwarf-Europe-flight-players-England-earning-average-2-3million-year.html>. Acesso em 24 dez. 2016.

HOBSBAWM, Eric J. Nações e nacionalismo desde 1780: programa, mito e realidade. Rio de Janeiro: Paz e terra, 2011.

JACQUES, Juliet. Diagne and the racial politics of Les Bleus. In bed with Maradona. 2010. Disponível em $<$ http:// inbedwithmaradona.com/journal/2010/11/14/diagne-and-the-racial-politics-of-les-bleus.html>. Acesso em 15 jul. 2014.

MENESES, Maria Paula G. O 'indígena' africano e o colono 'europeu': a construção da diferença por processos legais. E-cadernos CES, Coimbra, s/v, n. 07, 2010. Disponível em <https://eces.revues.org/pdf/403>. Acesso em 14 nov. 2016

MERLE, Isabelle. De la «légalisation» de la violence en contexte colonial: le régime de l'indigénat en question. Politix, Paris, v. 17, n. 66, 2004. Disponível em <http://www.persee.fr/docAsPDF/polix_0295-2319_2004_ num_17_66_1019.pdf>. Acesso em 13 nov. 2016.

MORIER-GENOUD, Eric; CAHEN, Michel. Introduction: Portugal, empire, and migrations - Was there ever an autonomous social imperial space? In: (Orgs.). Imperial migrations: colonial communities and Diaspora in the Portuguese world. Basingstoke: Palgrave Macmillan, 2012.

NOLASCO, Carlos. Entre a defesa e o ataque, os imigrantes do futebol português. In: CONGRESSO PORTUGUÊS DE SOCIOLOGIA, 7., 2012, Porto. Atas... Lisboa: Associação Portuguesa de Sociologia, 2012. Disponível em <http://www.aps.pt/vii_congresso/papers/finais/PAP0775_ed.pdf>. Acesso em 10 nov. 2016.

RIBEIRO, Margarida Calafate. Uma história de regressos: império, guerra colonial e pós-colonialismo. Oficina do CES, Coimbra, s/v, n. 188, 2003. Disponível em <http://www.ces.uc.pt/publicacoes/oficina/ficheiros/188.pdf>. Acesso em 11 nov. 2016.

SCHWARCZ, Lilia M. Imaginar é difícil (porém necessário). In: ANDERSON, Benedict. Comunidades imaginadas: reflexões sobre a origem e a difusão do nacionalismo. 2.ed. São Paulo: Companhia das Letras, 2008.

SPORT LISBOA E BENFICA. Avançados. Disponível em: <http://www.slbenfica.pt/SLB/Historia/GrandesJogadores/Avancados/tabid/309/mid/1456/dnnprintmode/true/language/pt-PT/Default.aspx?SkinSrc=[G]Skins\%2F_default\%2FNo+Skin\&ContainerSrc=[G]Containers\%2F_default\%2FNo+Container $>$. Acesso em 31 jul. 2014.

TOVAR, Rui Miguel. Espírito Santo, o primeiro negro na selecção portuguesa. Jornal I. 2011. Disponível em $<\mathrm{http}: / /$ www.ionline.pt/artigos/111812-espirito-santo-o-primeiro-negro-na-seleccao-portuguesa $>$. Acesso em 15 jul. 2014. 
VASILI, Phil. Exploding into maturity: the Seventies and the Eighties. In: . Colouring over the white line: the history of black footballers in Britain. Edimburgo: Mainstream Publishing Co., 2000.

VIDACS, Bea. France in the Cameroonian football imagination. In: ARMSTRONG, Gary; GIULIANOTTI, Richard (Orgs.). Football in Africa: conflict, conciliation and community. Basingstoke: Palgrave Macmillan, 2004.

Recebido em 09/01/2017

Aceito em 09/03/2018 